\title{
Retinopathy of valsalva secondary to bulimia nervosa: revision of the treatment with laser Nd-YAG
}

\section{Valsalva retinopathy secondary to bulimia nervosa: review of Nd-YAG laser treatment}

\author{
Julia A. Fajardo-Sánchez*, Pilar Rojas-Lozano and Carlos E. Chau-Ramos \\ Retina department, Hospital General Universitario Gregorio Marañón, Instituto Provincial de Oftalmología, Madrid, Spain
}

\begin{abstract}
19-year-old male under treatment for bulimia came for sudden decrease of the visual acuity (VA) of the left eye (LE) after an episode of severe vomit. The LE vision was of hand motion and the fundus showed a sub internal limiting membrane (subILM) hemorrhage of 14 disc diameters. We decided to use Nd-YAG laser on the membrane, obtaining the complete drainage of the hemorrhage and immediate recovery of the LE VA (20/20). Conclusion: Nd-YAG laser treatment is recommended for young and active patients in cases of sub-ILM hemorrhage in the context of Valsalva's retinopathy, due to its effective results and minimal risk.
\end{abstract}

Key words: Valsalva Retinopathy. Sub internal limiting membrane hemorrhage. Nd-YAG laser. Membranotomy. Bulimia nervosa.

\section{Resumen}

Varón de 19 años en tratamiento por bulimia nerviosa acude por disminución brusca de la agudeza visual (AV) en el ojo izquierdo tras un episodio de vómito. A la exploración se objetivó visión de movimiento de manos y hemorragia por debajo de la membrana limitante interna (sub-MLI) de 14 diámetros de papila. Se aplicó láser Nd-YAG sobre la lesión, y se obtuvo el drenaje completo de la hemorragia y la recuperación inmediata de la AV, que llegó a 20/20. Conclusión: Se recomienda el tratamiento de la hemorragia sub-MLI con láser Nd-YAG en pacientes jóvenes y activos con retinopatía de Valsalva debido a sus resultados efectivos, rápidos y con mínimo riesgo.

Palabras clave: Retinopatía de Valsalva. Hemorragia submembrana limitante interna. Nd-YAG laser. Membranotomía. Bulimia nerviosa.

Correspondence:

*Julia Andrea Fajardo-Sánchez

Aurelio Miro Quesada, 166

Date of reception: 07-02-2017

Date of acceptance: 01-03-2017

E-mail: juliafajardo7@gmail.com license (http://creativecommons.org/licenses/by-nc-nd/4.0/).
Available online: 01-11-2019 Rev Mex Oftalmol (Eng). 2019;93(6):294-298

www.rmo.com.mx hed by Permanyer México SA de CV. This is an open access article under the CC BY-NC-ND 


\section{Introduction}

Pre-macular hemorrhage in a previously healthy eye is a rare cause of visual acuity (VA) decrease. It can be caused by retinal neovascularization secondary to proliferative diabetic retinopathy or secondary to retinal vein occlusion, trauma, Terson syndrome, rupture of a retinal macroaneurysm or Valsalva retinopathy $(\mathrm{VR})^{1}$.

VR is a term coined by Duane ${ }^{2}$ in 1972 used to describe hemorrhages secondary to rupture of the superficial capillaries of the retina due to the Valsalva maneuver, which produces increased intrathoracic venous pressure with the consequent increase in ocular venous pressure ${ }^{3}$. Retinal hemorrhages described in VR include subhyaloid hemorrhage, vitreous hemorrhage and, those located under the internal limiting membrane (sub-ILM) as in our case ${ }^{4,5}$.

\section{Clinical case presentation}

A 19-year-old male patient with a diagnosis of bulimia nervosa and in treatment for recurrent episodes of self-induced vomiting. He attended the consultation due to a sharp VA decrease of the left eye (OS) after a vomiting episode. Examination revealed VA was of 20/20 in right eye (OD) (Snellen optotypes in letters, 6 meters) and hand motion in OS. Autorefractometer revealed -0.50 in OD and +3.50 in OS. The anterior pole of both eyes was normal. Intraocular pressure was $12 \mathrm{mmHg}$ in both eyes. Posterior pole of the OD did not show alterations; however, fundus of the OS revealed a large central hemorrhage at the premacular level, with involvement of the papillomacular bundle and part of the inferior temporal arcade, with an area of 14 disc diameters (DD) (Figs. 1 and 2, retinographies showing the hemorrhage). An imaging study using spectral domain optical coherence tomography (OCT) was performed (Fig. 3), showing the sub-ILM location of the hemorrhage. The diagnosis was a sub-ILM hemorrhage secondary to VR in the context of bulimia nervosa.

The initial management was expectant, monitoring the hemorrhage while waiting for its reabsorption. Nevertheless, after 2 weeks, the hemorrhage was unchanged and without a yellow discoloration that suggests the presence of clots, and the patient did not show VA changes. After verifying that the patient did not have systemic diseases or blood dyscrasias that contraindicated the procedure, it was decided to treat him with Nd-YAG laser using a contact lens for the posterior pole. A single laser shot was applied on the posterior hyaloid and ILM, at the central point of the

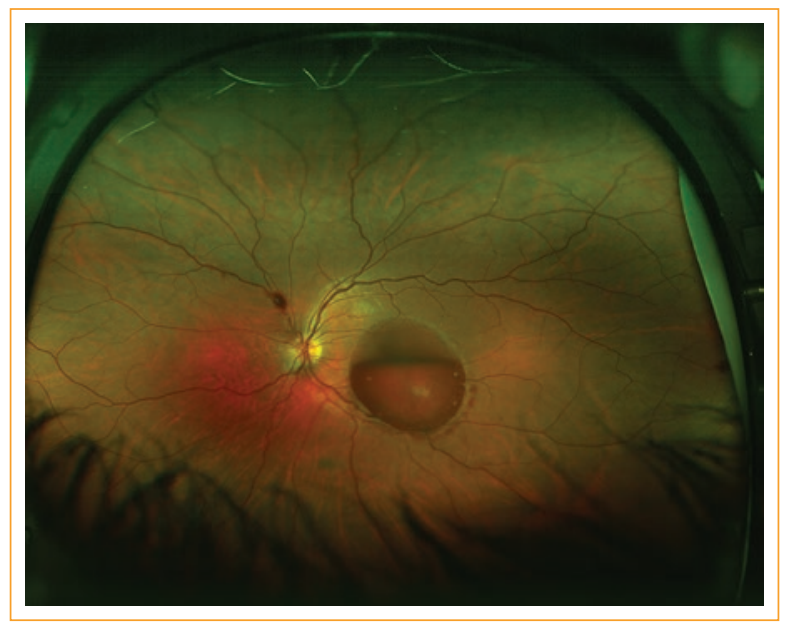

Figure 1. Sub-ILM premacular hemorrhage on the fovea and part of the inferior temporal vascular arcade. Hemorrhage area of 14 disc diameters.

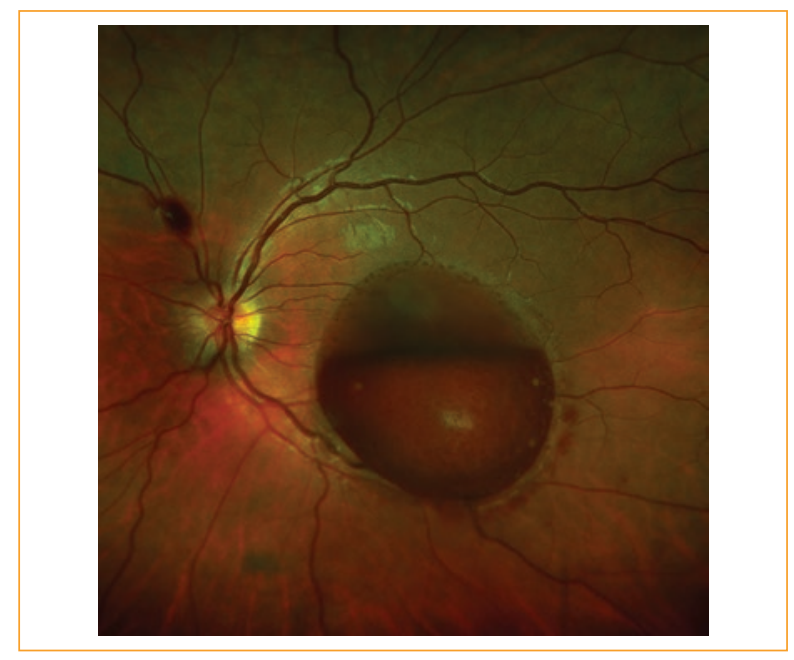

Figure 2. Magnification of the previously described lesion.

hemorrhage and at a height coinciding with the superior level of the boat-shaped hemorrhage. The energy used was $7.5 \mathrm{~mJ}$. The process was recorded by serial retinographies (Fig. 4, first shot). Complete drainage of the hemorrhage was observed (Figs. 5 and 6) at the end of the procedure. The patient recovered his previous VA, improving to $20 / 20$ without correction immediately after the procedure. The blood that drained to the vitreous cavity reabsorbed after two weeks (Fig. 7). Six months after treatment, the patient had a preserved VA, without complications.

\section{Discussion}

There is controversy about the location of premacular hemorrhages in cases of VR. If the hemorrhage is at 




Figure 3. Macular OCT of the premacular hemorrhage observed in previous retinographies. Hyperreflective, thick and bright line that continues with the adjacent retina and corresponds to the ILM, while the hyporeflective space below it corresponds to the hemorrhagic dome.

the subhyaloid level, the fundus will show a tenuous ring of low brightness and without folds; but if the hemorrhage is located below the ILM, an elevated dome with a consistent and bright appearance, a well-defined ring and presence of striae on the surface will be observed $^{6}$. If the blood is distributed at both levels, the double ring sign ${ }^{4}$ will be observed, where the external ring derives from the subhyaloid hemorrhage and the internal one from the sub-ILM.

On the other hand, OCT helps to confirm this location. If it is a sub-ILM hemorrhage, the blood will be observed as a hyporreflective space below a thick and bright hyperreflective line, with continuous borders and well delimitated, corresponding to the ILM. However, the posterior hyaloid will be observed as a weakly hyperreflective, discontinuous and thin line ${ }^{6,7}$. In our case, OCT (Fig. 3) showed that the hemorrhage is under a hyperreflective, bright and compact line that continues with the rest of the adjacent retinal tissue, suggesting an hemorrhage located sub-ILM.

It has been described the spontaneous resolution of retinal hemorrhages caused by VR after several months; however, such chronic exposure to hemoglobin and iron, oxidative components of the blood, may produce fibrovascular tissue at the vitreous-retinal interface and proliferation of the pigment epithelium ${ }^{3,4,8}$ 


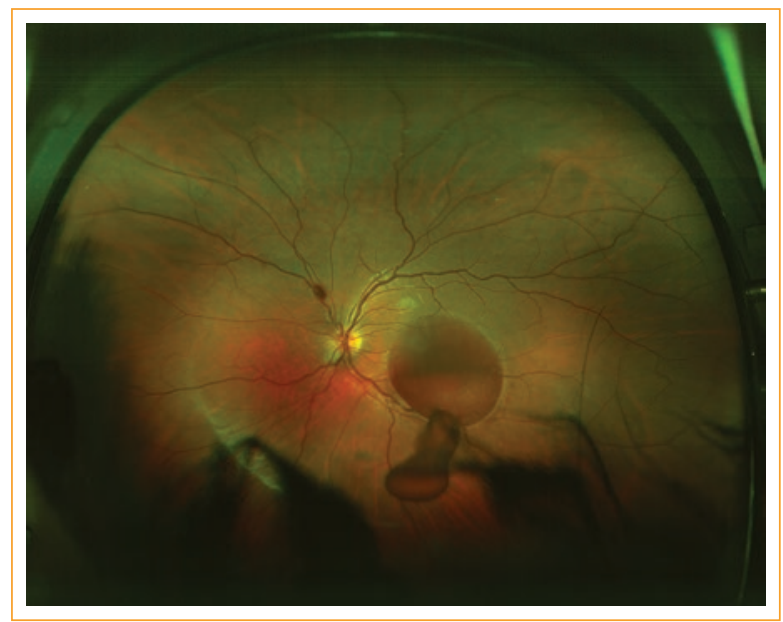

Figure 4. Nd-YAG single-shot (energy of $7.5 \mathrm{~mJ}$ ) on the most concave point of the hemorrhagic bursa.

Hemorrhage drainage is observed with persistence at the inferior level.

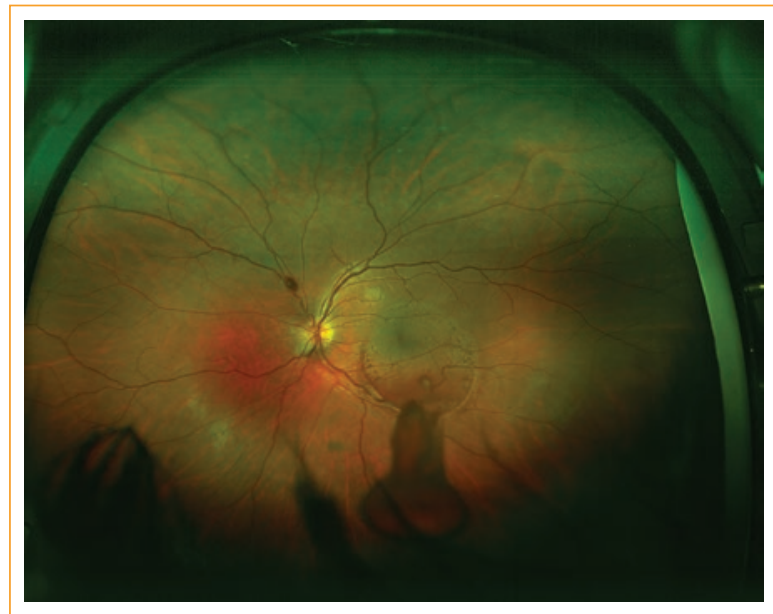

Figure 5. Drainage of the sub-ILM hemorrhage into the vitreous cavity through a single point.

as well as inducing an epiretinal membrane and photoreceptor toxicity, with a consequent permanent VA decrease $e^{9-11}$.

The first ones to report the use of Nd-YAG to open the anterior surface of the posterior hyaloid or ILM, with the consequent drainage of the blood to the vitreous, were Faulborn (1988) and Gabel (1989) ${ }^{12,13}$. It is important to consider when performing a laser membranotomy, due to the risk of retinal damage, that the convexity adopted by the posterior hyaloid and ILM with an hemorrhagic content allows the impact of the laser to be safer and far from the retina, which is why it is recommended that the shot impacts on the part with the highest volume, in the lower sector and far from the

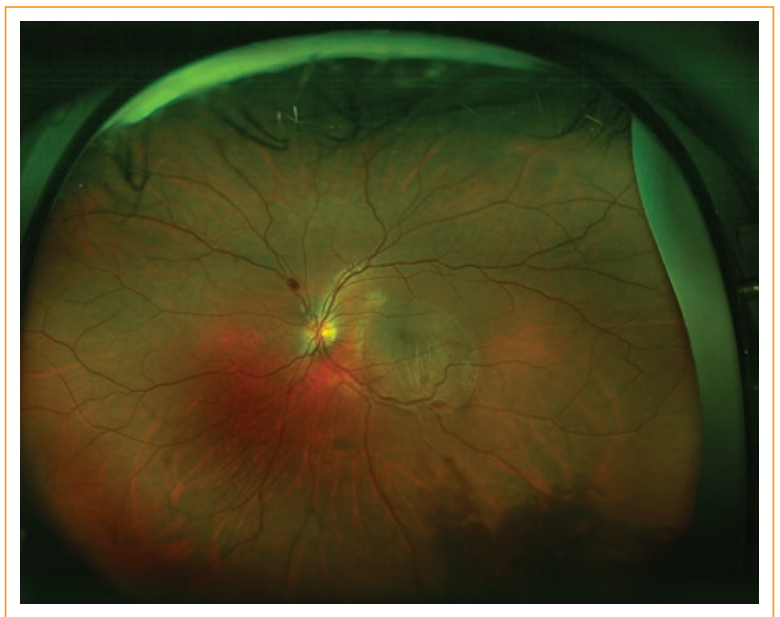

Figure 6. Premacular space without hemorrhage. Exposed fovea is observed.

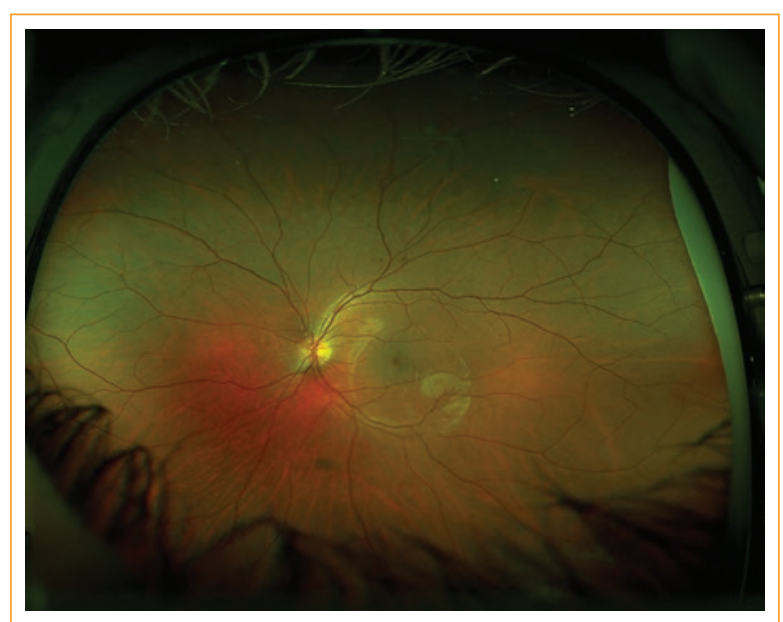

Figure 7. Retinography taken two weeks after laser treatment. The space that contained the hemorrhage persists. Folds can be seen on its surface. Vitreous cavity free of hemorrhage.

fovea ${ }^{4,8,14}$. Ulbig, et al., in a study of 21 eyes with subhyaloid premacular hemorrhage treated with $\mathrm{Nd}$ YAG, concluded that the minimum safety size required to perform the procedure was $3 \mathrm{DD}^{15}$. Durukan adds 1 DD to Ulbig's 3 DD for the performance of the membranotomy with an acceptable safety profile ${ }^{16}$. Regarding the energy of the laser, it has been described that it can be up to $50 \mathrm{~mJ}$ in these cases ${ }^{4,8}$.

The timing of the procedure is decisive for its success, since the complete drainage of the hemorrhage depends on its ability to flow through the perforation. Most authors report a successful drainage before 3 weeks of the episode, probably due to the still preserved 
fluidity of the blood and the instability of the clots already formed $3,4,14,15,17$.

Potential complications of the procedure include the appearance of an epiretinal membrane, localized increase of the thickness of the ILM and persistence of a minimal subhyaloid cavity $3,11,17$.

\section{Conclusions}

Membranotomy with Nd-YAG is an effective alternative to the classic treatment of pre-macular hemorrhage secondary to VR, since it allows early visual recovery and has an acceptable safety profile; it is also a comfortable and accessible treatment that can be performed in most practices. It also prevents the potential damage that blood induces when in contact with the retina.

\section{Ethical disclosures}

Protection of human and animal subjects. The authors declare that no experiments were performed on humans or animals for this study.

Confidentiality of data. The authors declare that they have followed the protocols of their work center on the publication of patient data.

Right to privacy and informed consent. The authors have obtained the written informed consent of the patients or subjects mentioned in the article. The corresponding author is in possession of this document.

\section{Conflicts of interest}

The authors declare no conflicts of interest.

\section{References}

1. Tariq Khan M. Nd: YAG laser treatment for Valsalva premacular hemorrhages: 6 month follow up. Int Ophthalmol. 2008;28:325-7.

2. Duane TD. Valsalva hemorrhagic retinopathy. Am J Ophthalmol. 1973;75:637-42

3. Liu Z, Pan X, Bi H. Treatment of Valsalva Retinopathy. Optom Vis Sci. 2014:91(11):e278-81.

4. Mathew D, Sarma S. Valsalva retinopathy with double ring sign: laser membranotomy for twin bleeds. Saudi J Ophthalmol. 2016;30:68-70.

5. Cheung CM. Post-chemotherapy premacular subhyaloid haemorrhage. Eye. 2003;17:97-9.

6. Meyer $\mathrm{CH}$, Mennel S, Rodrigues EB, Schmidt JC. Is the location of Valsalva hemorrhages submembranous or subhyaloidal? Am J Ophthalmol. 2006;141(1):231.

7. Tirhis H. Argon Green Laser for valsalva retinopathy treatment and longterm follow up of the internal limiting membrane changes in optical coherence tomography. Korean J Ophthalmol, 2015;29 (6):437-8.

8. Kuruvilla O. NdYAG membranotomy for preretinal hemorrhage secondary to valsalva retinopathy. Saudi J Ophthalmol. 2014;(28):145-51.

9. Duane TD. Valsalva hemorrhagic retinopathy. Trans Am Ophthalmol Soc. 1972;70:298-313.

10. De Maeyer K, Van Ginderdeuren R, Postelmans L, Stalmans P, Van Calster J. Sub-inner limiting membrane haemorrhage: causes and treatment with vitrectomy. Br J Ophthalmol. 2007;91:869-72.

11. Gibran SK, Kenawy M, Wong D, Hiscott $P$. Changes in the retinal inner limiting membrane associated wih Valsalva retinopathy. Br J Ophthalmol. 2007;91(5):701-2.

12. García Fernandez M. Long Term evolution of Valsalva retinopathy: a case series. J Med Case Rep. 2012;6:346.

13. Faulborn J. Behandlung einer diabetischen pramakulares Blutung mit dem Q switched Neodym: YAG laser. Spektrum Augenheilkd. 1988;2:33-5.

14. Gabel VP. Nd: YAG laser photodisruption of hemorrhagic detachment of the internal limiting membrane. Am J Ophthalmol. 1989;107:33-7.

15. Ulbig MW. Long-term results after drainage of premacular subhyaloid hemorrhage into the vitreous with a pulsed Nd: YAG laser. Arch Ophthalmol. 1998;116:1465-9

16. Durukan $\mathrm{AH}$. Long term results of $\mathrm{Nd}$ : YAG laser treatment for premacular subhyaloid haemorrhage owing to valsalva retinopathy. Eye. 2008;22:214-8.

17. Sabella P, Bottoni $F$, Staurenghi G. Spectral domain OCT evaluation of NdYAG laser treatment for Valsalva retinopathy. Graefes Arch Clin Exp Ophthalmol Albrecht Von Graefes Arch Für Klin Exp Ophthalmol. 2010;248:599-601. 